\title{
EDITORIAL
}

\section{Around the sun in 12 issues}

Join us in celebrating the first anniversary of Nature Reviews Earth \& Environment.

Let's face it, 2020 was tough. For that reason, here at Nature Reviews Earth \& Environment we decided to celebrate the wins, however small, in an attempt to bring some positivity and optimism back into our daily lives. So what are we celebrating? The first birthday of Nature Reviews Earth \& Environment! Of course, launching a journal and achieving this anniversary would not have been possible without the hard work of our authors and peer reviewers who, despite all the trials that 2020 brought, have offered their time, patience and energy - from the bottom of our hearts, thank you!

Over the past year, we hope that you have started to get a sense of what Nature Reviews Earth \& Environment is about: providing timely, authoritative syntheses of geoscience research. Needless to say, it's impossible to showcase all subject areas within a mere 12 issues, but having featured articles on fast fashion, erosional landscapes, pyroclastic density currents, wildfires, subduction erosion and tropical fisheries, to name just a few, we would like to think there is something for everyone, novice and expert alike. Indeed, a staggering 300,000 people viewed our articles in 2020. In an accompanying online Collection, we have selected a few articles from our launch year that highlight our diversity. However, with an even wider array of topics promised for 2021 (teaser: evolution of the biosphere, slow slip earthquakes, precipitation extremes, drylands, geothermal energy and permafrost), it's worth registering for e-alerts or following us on social media (@NatRevEarthEnv) to stay up to date.

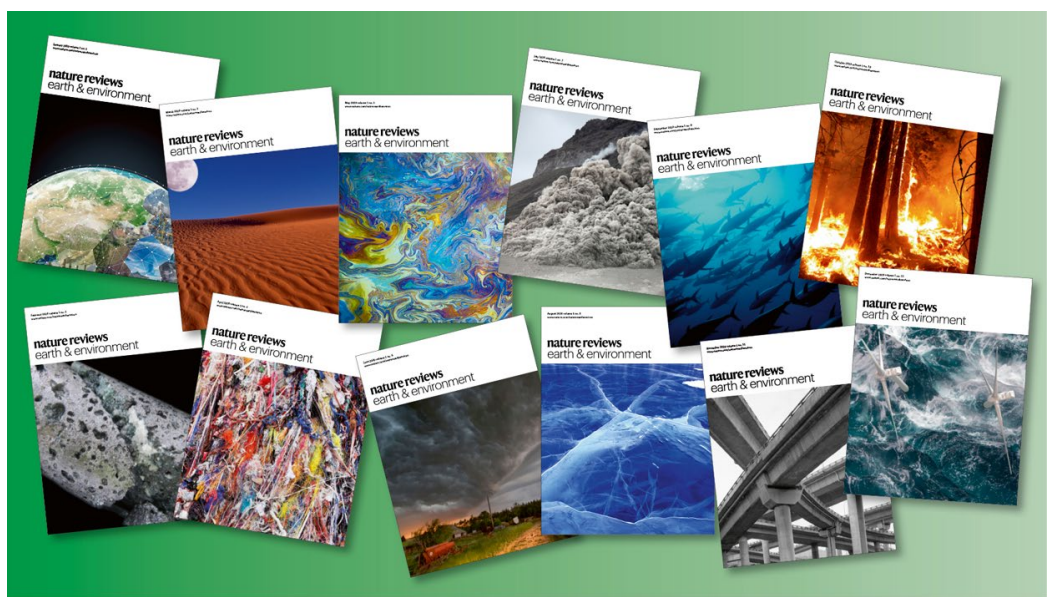

While much of a Review is focused on synthesising existing research, at its core is a motivation to facilitate and encourage new advances; what don't we know and how can we find it out? This fusion of past developments and future prospects is reflected in three Viewpoint articles included in this Issue. Researchers spanning multiple topics within weather and climate, surface processes, and solid Earth research - were asked to discuss key developments in their field and outline where they think progress is needed. Sarah Perkins-Kirkpatrick, for example, comments how a data revolution in the mid-2000s allowed for better quantification of extreme events, but calls for a similar disruption in modelling physical mechanisms to advance knowledge of, and confidence in, future projections. Irasema Alcántara-Ayala further describes the need for academic and non-academic collaboration in landslide risk research, with the goal of producing knowledge that can be transferred to policies and practices that effect better disaster risk reduction.

However, it is not only academic progress that our experts called for, but also fundamental changes within the community. For instance, Adelle Thomas outlines how the global Black Lives Matter movement brought to light the marginalization of Black climate experts due to systemic racism in academia, and Christy Till argues that individual actions and commitments are required now to create a more inclusive scientific community. At Nature Reviews Earth \& Environment, we are committed not only to ensuring our articles represent diverse voices, but also that the journal is a platform to raise, provide solutions to, and discuss community issues.

Indeed, listening to these community needs and desires and providing articles that are genuinely useful is the journal's raison d'être. COVID-19 has clearly hampered many of the traditional opportunities for editor-community interactions, but we are here and we are listening. We've attended virtual conferences, participated in virtual panel discussions, organized virtual talks on publishing, and had many virtual chats with the community. We all miss the personal interactions and ideas that stem from that, but if you want to speak to us, please reach out.

To all our readers, authors and peer reviews, thank you once again for helping us get Nature Reviews Earth \& Environment to this point despite such a hectic 2020. Here's to smoother sailing and good health for all in 2021. 